\section{ECCOMAS}

\section{Proceedia}

COMPDYN 2021

$8^{\text {th }}$ ECCOMAS Thematic Conference on Computational Methods in Structural Dynamics and Earthquake Engineering M. Papadrakakis, M. Fragiadakis (eds.) Streamed from Athens, Greece, 28 - 30 June 2021

\title{
REINFORCING STOP-SPLAYED SCARF JOINTS WITH TIMBER PEGS: ROLE OF SLENDERNESS
}

\author{
C. Ceraldi ${ }^{1}$, C. D’Ambra ${ }^{1}$, M. Lippiello ${ }^{1}$, A. Sandoli ${ }^{1}$ and A. Prota ${ }^{1}$ \\ ${ }^{1}$ Department of Structure for Engineering and Architecture, University of Naples "Federico II" \\ via Claudio 21, 80125, Naples \\ e-mail: \{carla.ceraldi,claudio.dambra,maria.lippiello, antonio.sandoli,andrea.prota\}@unina.it
}

\begin{abstract}
Repairing stop-splayed scarf-joints in beams or truss-rods is a frequent occurrence in restoring ancient timber structures. Reinforcement of carpentry joints by means of metallic elements as well as unconventional materials is extensively investigated in literature, while timber pegs in timber to timber connections are studied referring mainly to new timber structures.

In the present paper, authors' previous research analysing the mechanical behaviour of stopsplayed scarf joints reinforced with timber pegs has been carried on, focusing on the evaluation of ductility which can be achieved by reinforcement with timber pegs. Moreover, the role of slenderness, the rate between jointed timber thickness and peg diameter is analysed.

An experimental program has been carried out testing in axial tension two samples of fir scarf joints with an ash key: one sample constituted of two simple scarf joints, and one constituted of three scarf joints reinforced with two ash pegs of $20 \mathrm{~mm}$ of diameter. Comparing experimental results has allowed to better understand the role played by timber pegs in reinforcement and to evaluate the influence of reinforcement on ductility of reinforced scarf joints behaviour.

Experimental results have also been compared with those obtained in a previous experimental study where an analogous experimental program has been made on smaller scarf joints reinforced with two ash pegs of $8 \mathrm{~mm}$ of diameter. So, the role played by slenderness has been focused.

The evaluation of the attained results, even if not exhaustive for a reliable theoretical formulation of timber peg behaviour in reinforcing stop-splayed joints, has allowed the identification of some interesting features, that is stiffness and reinforcement due to timber pegs.
\end{abstract}

Keywords: stop-splayed scarf joint, reinforcement, timber peg, ductility, slenderness, timber structures. 


\section{INTRODUCTION}

In the field of ancient timber structures restoration, the need of substituting rotten portions of structural elements, preserving the original spatial configuration without modifying their structural behavior is advisable. At this aim, when total or partial substitution of an element is needed, the employment of traditional carpentry joints normally leads to a more conservative approach. In particular, in ancient trusses and floors, taking off the end portions of rafters or beams, damaged by biotic agents often due to high moisture content inside the masonry walls, is sometimes inevitable.

A quite speared methodology of restoration envisages the introduction of new timber elements connected to the standing structure. This connection is generally realized with metallic bolted plates, steel pins, or epoxy resin adhesives. According to their arrangement and geometry, common traditional carpentry joints can be divided in four main types: a) tenon and mortise joints; b) notched joints; c) lap joints and d) scarf joints. These connections are generally fixed or reinforced with metallic connectors, or epoxy resin adhesive, even if some disadvantages may occur such as (i) moisture condensing problems in the interface between timber and steel elements, (ii) questionable aesthetic output in uncovered structures, and (iii) the difficult reversibility of the intervention with resin adhesives [1,2]. Nowadays an efficient alternative is the use of timber pegs in timber to timber connections. In literature, reinforcement of carpentry joints by means of metallic elements, as well as unconventional materials, is extensively investigated, while fewer papers can be found regarding the employment of timber pegs. In a review paper by Branco and Descamps [3] a state of art is described where many interesting references are quoted concerning the main themes as modelling and simulation of analysis and strengthening of carpentry joints. Moreover, several papers focusing on birds mouth joint $[1,2]$, mortise and tenon joint [4-6], and dowel joint [7, 8] can be found. A general overview regarding lapped scarf joints is presented by Kunecký et al. [9] in which the stiffness assessment of jointed structural elements for different joint positions and element sizes is investigated. ArciszewskaKędzior et al. [10] performed both experimental and numerical analyses to study the mechanical behavior of a lapped scarf joint with inclined contact faces and four oak dowels. Sangree and Schafer [11] presented an experimental study on the mechanical behavior of a stop-splayed scarf joint with transverse key. Mechanical tests on four specimens simulating real joints have been performed and the study has been completed using a three-dimensional finite element model created using ABAQUS. Ceraldi et al. [12] analyze the mechanical behavior of stopsplayed scarf joints unreinforced and reinforced with timber pegs and with steel pins, subjected to tension test, to assess the reliability of employing timber fasteners. The role of the fastener inside this tensile-resistant carpentry joint and its contribution in yield strength and stiffness have been investigated. Aira et al. [13] experimentally analyze the structural behavior of halved and tenoned scarf joint subjected to tensile stresses in order to describe the different failure modes. In Perria et al. [14] results of an experimental campaign and an analytical model for the behavior of the halved under-squinted scarf joint are presented. Different aspects that influence the behavior of the connection subjected to pure compression, pure bending and combined compression and bending are analyzed. The stiffness of scarf joints with keys and timber pegs has been investigated and modelled by Fajman and Màca [15], including the role of friction forces, already studied in [16]. An experimental evaluation of traditional scarf joinery behavior in bending can be found in Hirst et al. [17]. More recently, in Karolak et al. [18] a more in-depth analysis on the current state of knowledge related to scarf and splice carpentry joints in flexural elements as well as selected examples of tensile elements is presented.

The rheological behavior of timber to timber joints connected by timber pegs, its modelling and the formulation of corresponding design rules, can be more extensively found in literature 
referred to new structures, such as timber frames. Generally, research about timber peg behaviour in simple and double shear plane joints fastened with timber pegs and its theoretical and numerical interpretation aims to the identification of codified design rules, usually starting from those derived from Johansen's theory [19] prescribed for calculating strength capacity of steel fasteners [20-23]. Design rules validated for mortice and tenon joints have been proposed in $[24,25]$. Many research, instead, have investigated the role of the different parameters influencing the joint behavior: rate of diameter and timber board thickness [21]; dowel bearing strength $[22,26,27,28]$; shear and bending of the peg [19, 29, 30, 31]; direction of the load [32]; ductility [21, 33, 34, 35].

In the present paper, authors' previous research analyzing the mechanical behaviour of stopsplayed scarf joints reinforced with timber pegs has been carried on, focusing on the evaluation of ductility which can be achieved by reinforcement with timber pegs.

Ductility describes the ability of a structure to attain large deformation in the plastic range before its collapse. In timber structures, it may predominantly be supplied by plastic behaviour of the connections which are the critical regions for load transfer. There are several definitions of ductility, all related to stress, strain or energy, which may be useful in different situations [34]. For connection design, definitions referring to absolute values of rotation and displacement may be the most applicable [33]. Also, ductility may further be divided into static ductility for constant loads, and dynamic ductility for cyclic loads [33]. Commonly, it is defined as the ratio between ultimate and yield displacement, according to the European code EN 12512 [36] and the Swiss code SIA 265 [37] for timber structures.

Since knowledge of the yield point and ductility of a structure is important in seismic design, their investigation has become more and more of interest within recent years. From structural engineering point of view in general and for timber engineering, there is not a unified definition of the ductility term, nor is there a common understanding on how ductility shall be used in structural design. As a result, several methods have been developed in order to determinate the point of yield and, consequently several measures for evaluating of the ductility of timber structures and connections are obtained. In Northern America is widely used the equivalent energy elastic-plastic method (EEEP); in the European code EN 12512 (CEN method) the 1/6 method is adopted [36]; the $0.5 \mathrm{~F}_{\max }$ method so as deduced from Karacabeyli and Ceccotto and finally, according to Yasamura and Kawei, the 10-40-90 method are also employed. A detailed description and discussion of those different methods can be found in [33]. According to these approaches, the evaluation of ductility can be carried out on the analysis of the load- displacements diagrams resulting from experimental tests or, alternatively, on approximating curves. This paper is focused on comparing two analysis methods commonly used in determination of yield load and deformation and of failure load and deformation, respectively.

An experimental program has been carried out testing in axial tension two samples of fir scarf joints with an ash key: one sample constituted of two simple scarf joints, and one constituted of three scarf joints reinforced with two ash pegs of $20 \mathrm{~mm}$ of diameter. Comparing experimental results has allowed to better understand the role played by timber pegs in reinforcement and to evaluate the influence of reinforcement on ductility of reinforced scarf joints.

Experimental results have also been compared with those obtained in a previous experimental study where an analogous experimental program has been made on smaller scarf joints reinforced with two ash pegs of $8 \mathrm{~mm}$ of diameter. So, the role played by slenderness has been focused.

The evaluation of the attained results, even if not exhaustive for a reliable theoretical formulation of timber peg behaviour in reinforcing stop-splayed joints, has allowed the identification of some interesting features, that is stiffness and reinforcement due to timber pegs. 


\section{EXPERIMENTAL PROGRAM}

\subsection{Samples and test set-up}

The experimental program concerns two samples of stop splayed scarf joints made of fir, (Abies alba) with a key made of ash, (Fraxinus excelsior), whose dimensions and geometry are illustrated in Figure 1.

Sample A_D20 consists of two unreinforced joints, while sample B_D20 is constituted by three specimens of the same type of sample A_D20 but reinforced with two ash pegs with diameter of 20 millimeters (Figure 1).

Proportions and limit dimensions recommended for traditional configuration of scarf joints, with length three times the height of the cross section, have been assumed in their design.
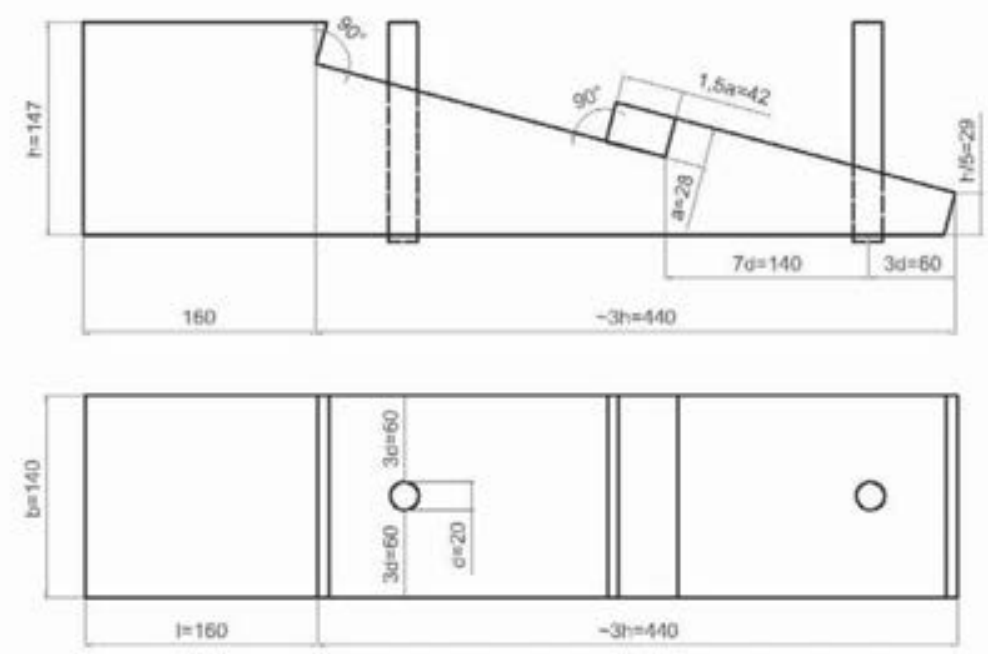

Figure 1: Specimen geometry of samples A_D20 e B_D20 (dimensions in $\mathrm{mm}$ )

Density and parallel to grain compression strength $\left(\sigma_{c, 0}\right)$ of the two employed essences quoted in Table 1 have been experimentally determined in previous research $[22,31]$ with an average moisture content approximately equal to $12 \%$.

\begin{tabular}{ccc}
\hline Timber & Density $\left(\mathrm{kg} / \mathrm{m}^{3}\right)$ & $\sigma_{\mathrm{c}, 0}(\mathrm{MPa})$ \\
\hline Ash & 652 & 56.3 \\
\hline Fir & 472 & 39.2
\end{tabular}

Table 1: Mean values of density and parallel-to-grain compression strength.

Samples have been tested in tension with a universal electromechanical test machine with hydro pump LOSENHAUSENWERK, Mod: UHP 60, electronic control with control unit Zwick Roell, (Figure 2), in displacement control, at a speed of $0.8 \mathrm{~mm} / \mathrm{min}$, until a complete loss of bearing capacity was reached. 


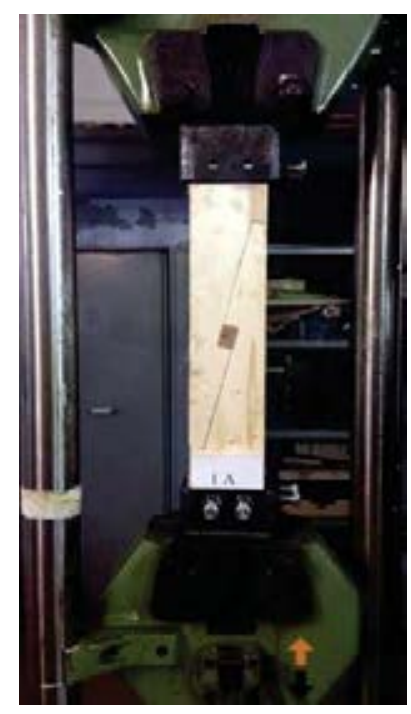

Figure 2: Test set-up

\subsection{Unreinforced sample (Sample A_D20)}

Final collapse of an unreinforced scarf joint with a key loaded in tension [32], can occur on the following critical surfaces: $(i)$ compression failure at key contact inclined surface (notch area), (ii) shear failure through the horizontal plane in the heel surface, (iii) combined tension and bending failure at the reduced section above the notch and (iv) compression failure perpendicular to grain of the key (Figure 3).
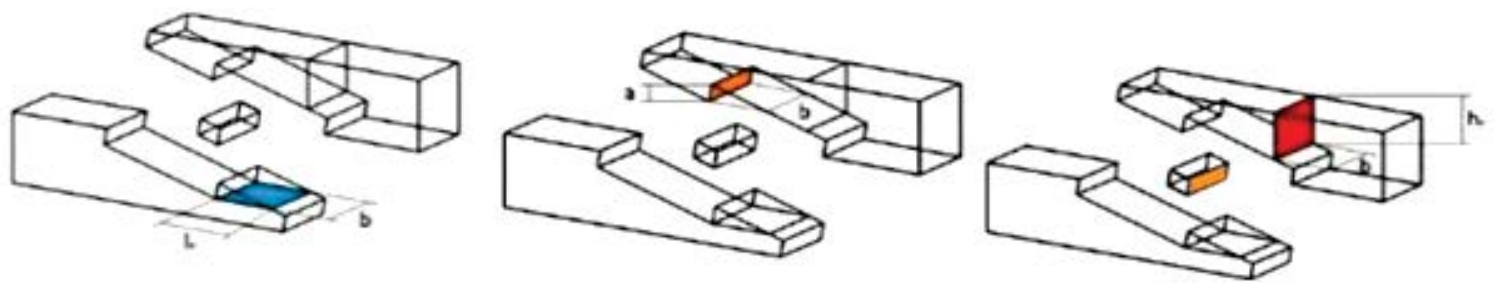

Figure 3: Failure surfaces of an unreinforced scarf joint with a key

Both specimens of sample A_D20 have failed due to shear stresses through the heel area (Figure 4). Force-displacement diagrams (Figure 5) show that the observed behavior can be schematized with two linear steps: the elastic one, and, after the yielding point, the plastic one, with a relevant hardening. Stiffness, which is governed only by the level of confinement of the key, increases in the plastic phase, due to the enforcement of the key, which has shown no deformation at all after collapse of both unreinforced joints. In specimen 1A_D20 this increase is more than in specimen 2A_D20 as its elastic stiffness is $26 \%$ of the plastic one, while that of test 2A_D20 is $35 \%$. 

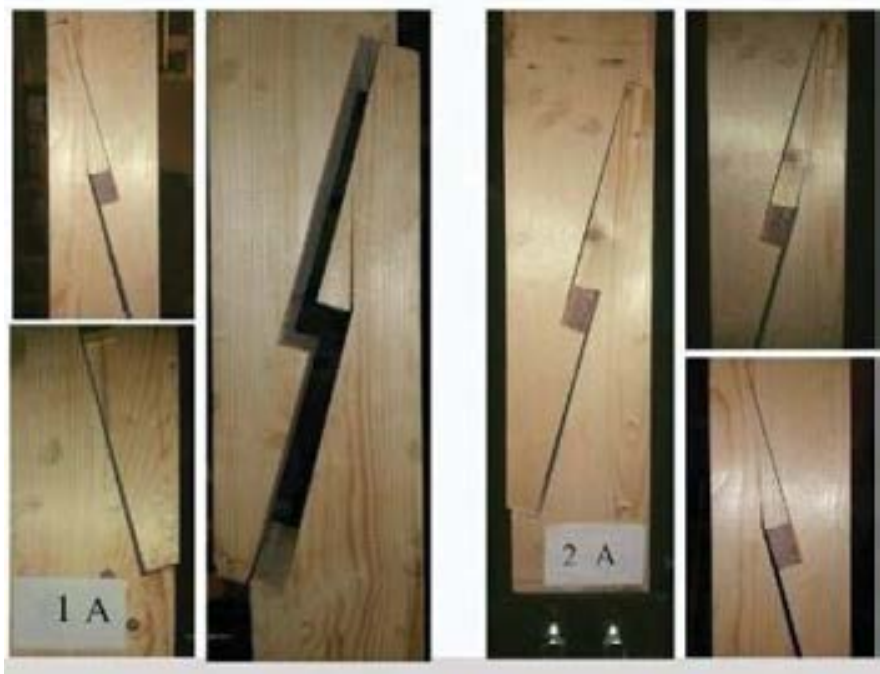

Figure 4: Failure mode of specimens 1A_D20 e 2A_D20

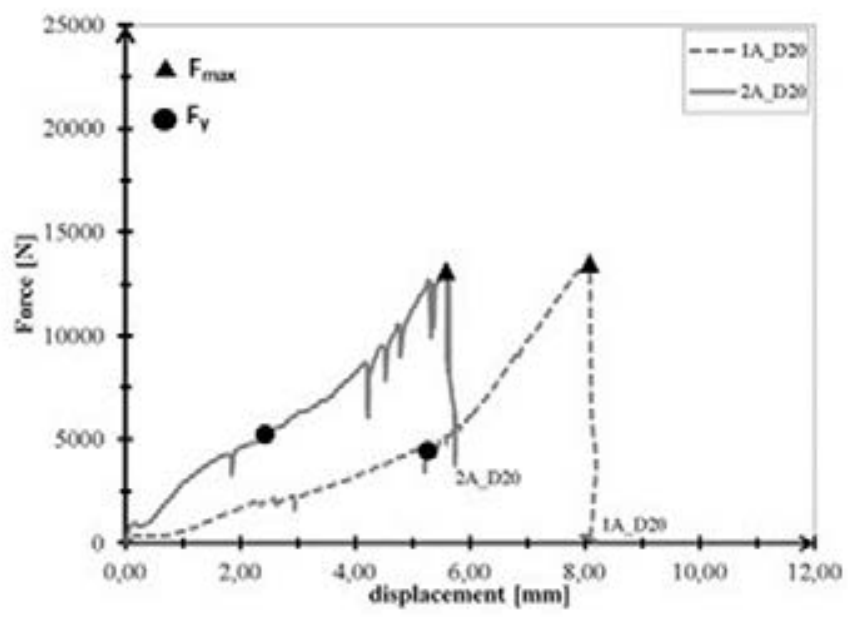

Figure 5: Force-displacement diagrams of sample A_D20

\subsection{Sample reinforced with pegs (Sample B_D20)}

In addition to the failure mode on the critical surfaces of a scarf joint with key, the reinforced joint can collapse in the single plane shear joint for embedment of the connected parts or failure of the peg in bending or "effective peg shear" failure mode, which is a combination of peg shearing, peg bending and embedding of timber boards [31].

Specimens 1B_D20 e 2B_D20 have both failed due to shear stresses through the heel area, while bending of the peg and embedding in the connected zone have been of little intensity in the first test and absent in the second. The key hasn't shown deformations (Figure 6). 


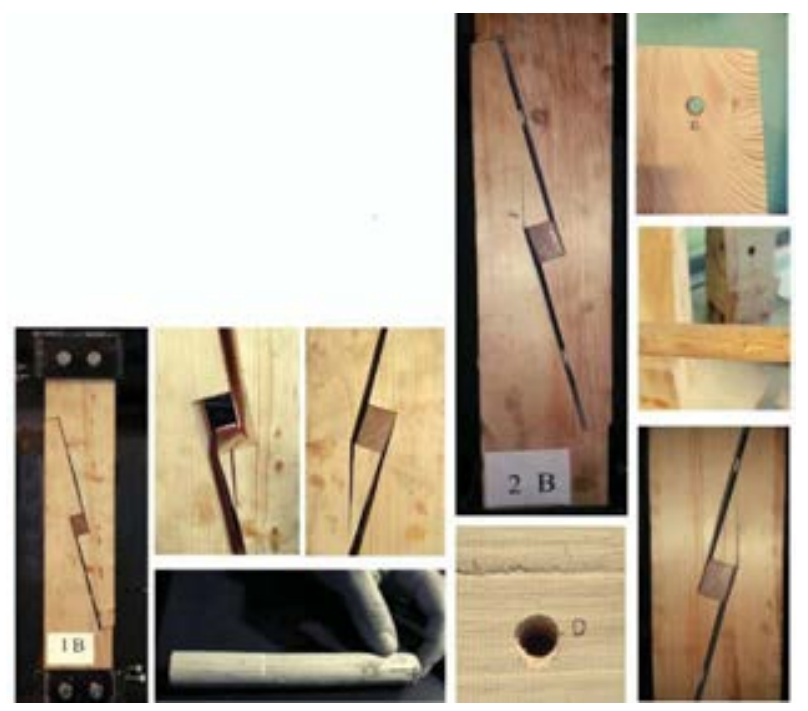

Figure 6: Failure mode of specimens 1B_D20 e 2B_D20

Specimen 3B_D20 has shown a different failure mode as collapse has been determined by embedding of the lower connection, with scarce deformation in the pegs, while the key has been undeformed (Figure 7).
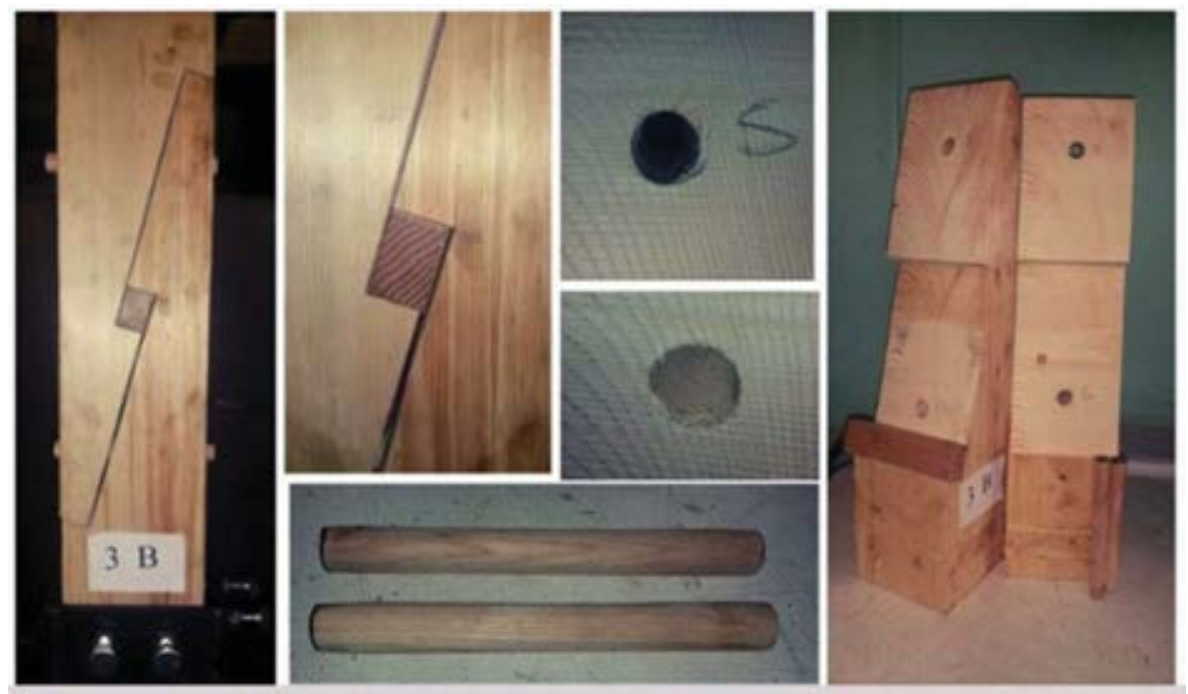

Figure 7: Failure mode of specimen 3B_D20

Comparing force-displacement diagrams for sample B_D20, quoted in Figure 8, it can be noted that only the specimen 2B_D20 doesn't have the ductile phase expected for the presence of the pegs [12], as collapse has been attained without deformations in the peg connection. Nonetheless, while specimens 2B_D20 and 3B_D20 present the same behaviour until the rupture of the first, specimen 1B_D20 differs from both. During the test of specimen 1B_D20, an initial crack developed in the notch area, parallel to the grain. This splitting due to tension perpendicular to the grain induced by compression parallel to the grain of the fibres, has generated a little crack which has not extended to the edge of the joint, as the presence of the peg connections delayed this occurrence, which at the end has induced shear collapse in the heel area. 


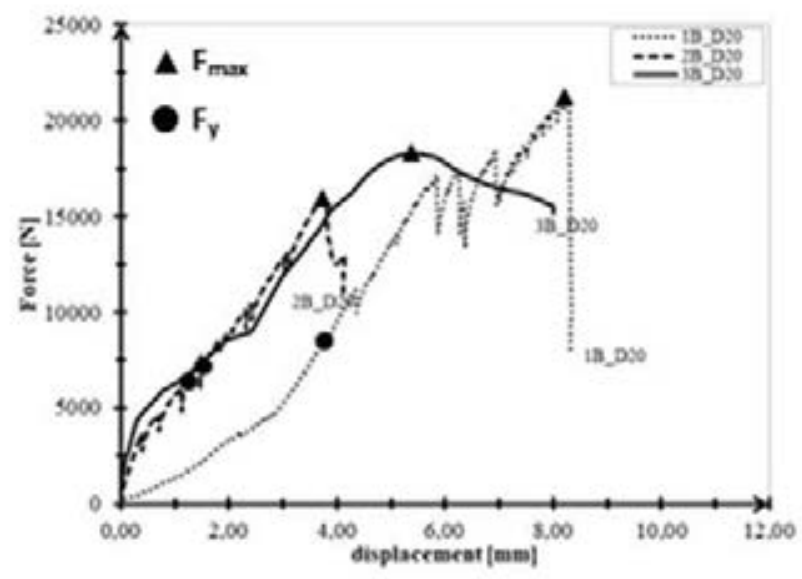

Figure 8: Force-displacement diagrams of sample B_D20

\subsection{Discussion of experimental results}

In Table 2 yielding force $\mathrm{F}_{\mathrm{y}}$ and maximum force $\mathrm{F}_{\max }$ values are summarized, together with corresponding displacement. In sample B_D20, due to the presence of the peg, the yielding point has been determined following the American procedure ASTM 5764 [38], consisting in choosing as yield point the intersection of the load-displacement curve with a straight line parallel to the linear phase of the diagram shifted to a distance equal to $5 \%$ of fastener diameter.

\begin{tabular}{c|ccccc} 
Specimen & $\begin{array}{c}\mathbf{d} \\
\mathbf{m m}\end{array}$ & $\begin{array}{c}\mathbf{F}_{\mathbf{y}} \\
\mathbf{( N )}\end{array}$ & $\begin{array}{c}\mathbf{u}_{\mathbf{y}} \\
\mathbf{m m}\end{array}$ & $\begin{array}{c}\mathbf{F}_{\mathbf{m a x}} \\
\mathbf{( N )}\end{array}$ & $\begin{array}{c}\mathbf{u}_{\mathbf{f}} \\
\mathbf{m m}\end{array}$ \\
\hline 1A_D20 & 20 & 11664.1 & 8.1 & 13514 & 8.1 \\
2A_D20 & 20 & 10025.0 & 5.6 & 13129 & 5.6 \\
1B_D20 & 20 & 16507.5 & 8.3 & 21227 & 8.2 \\
2B_D20 & 20 & 14701.3 & 3.8 & 15959 & 3.7 \\
3B_D20 & 20 & 16590.3 & 4.4 & 18340 & 5.4 \\
\hline
\end{tabular}

Table 2: Force and displacement values for sample A_D20 e B_D20

The reduced number of performed tests doesn't allow choosing a diagram fully representative of each sample behavior; so, with aim of comparing the rheological behavior of the two samples, all the diagrams are together compared in Figure 9.

The reinforcement with timber pegs is resulted efficient as it has induced a considerable increase of yielding and maximum forces values with respect to the unreinforced sample. In fact, sample B_D20 mean values $F_{y}$,mean $=15933 \mathrm{~N}$ and $F_{\text {max,mean }}=18509 \mathrm{~N}$ are $47 \%$ and $39 \%$ larger than the corresponding values of sample A_D20 $\mathrm{F}_{\mathrm{y} \text {,mean }}=10845 \mathrm{~N}$ and $\mathrm{F}_{\text {max,mean }}=13322$ $\mathrm{N}$. This enforcement can be ascribed to the interaction between the timber peg and the joint, which has delayed the failure along the typical critical surfaces of the scarf joint. So, a reliable prediction of load-bearing capacity of the reinforced stop-splayed scarf joint depends upon evaluating the amount of load transferred to the joint, inducing the collapse of critical surfaces, as observed in [12]. 


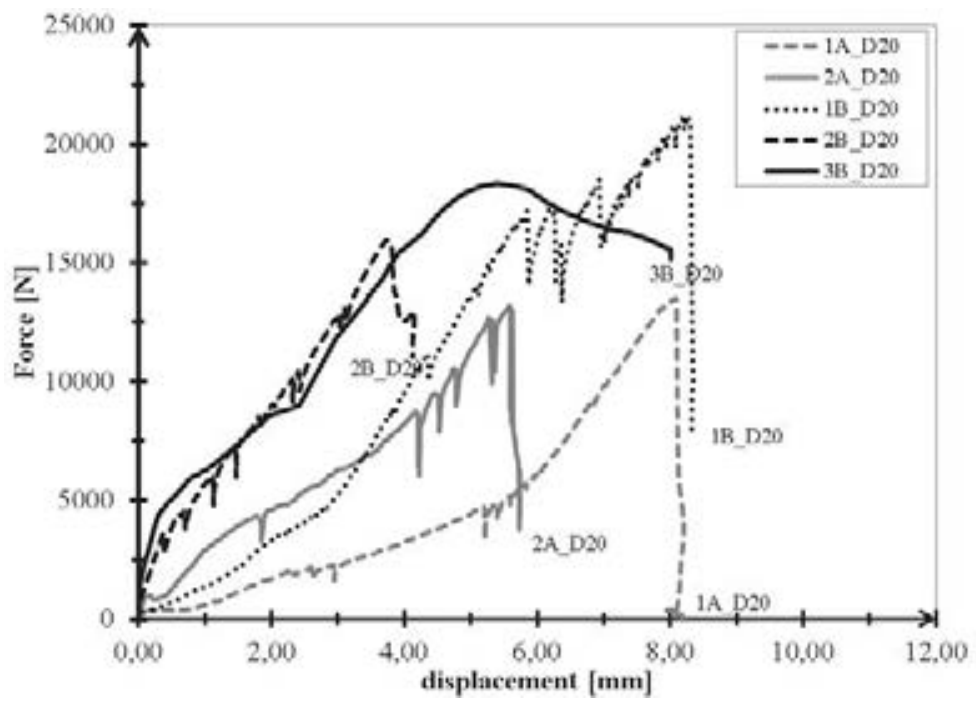

Figure 9: Comparison of force-displacement diagrams of samples A_D20 and B_D20

The observed rheological behaviors are quite different both in elastic and plastic range. While sample A_D20 shows a liner response in the elastic as well as in the plastic phase, sample B_D20, when deformation appears in the simple shear plane joint constituted by the timber peg connection, shows a stiffer behavior in the elastic phase and a more ductile behavior, in the plastic one. In fact, the overall behavior of the reinforced joint is conditioned by the force distribution among the resisting elements, i.e., the ash key and the added fasteners, which act as damping elements in transferring loads. Moreover, the stiffening effect can be related to the friction forces generated by the contact between the two timber elements, which help hold tight the connection and enhance the level of confinement of the key. The presence of no negligible friction forces when timber pegs are used and the influence of the key on the joint axial stiffness have been already noticed and measured in $[11,15,16]$, highlighting that the more the key is confined, the stiffer is the joint behavior.

\section{INFLUENCE OF SLENDERNESS ON DUCTILITY}

\subsection{Ductility}

Ductility is related to the ability of a structure to attain large deformations in the plastic range before its collapse and without substantial reduction in strength in specimen loaded in displacement control. There are several definitions of ductility, all related to stress, strain, or energy, which may be useful in different situations. For connection design, definitions referring to absolute values of rotation and displacement may be the most applicable (see [33]).

Commonly, ductility ratio is defined as the proportion of the displacement at failure $u_{\mathrm{f}}$ to the displacement at yielding $\mathrm{u}_{\mathrm{y}}$, so as deduced in the European and Swiss codes [36,37], which is given by:

$$
\mathrm{D}_{\mathrm{f}}=\frac{\mathrm{u}_{\mathrm{f}}}{\mathrm{u}_{\mathrm{y}}}
$$

An additional definition of the ductility ratio is also based on the displacement $u_{u}$ at ultimate load $\mathrm{F}_{\mathrm{u}}$ and it is represented by the following equation: 


$$
\mathrm{D}_{\mathrm{u}}=\frac{\mathrm{u}_{\mathrm{u}}}{\mathrm{u}_{\mathrm{f}}}
$$

These parameters can be determined from the analysis of the load-displacements graphs resulting from experimental tests. The displacement at yield $\mathrm{u}_{\mathrm{y}}$, with the corresponding yielding load $F_{y}$, describes the point where the elastic behavior passes into a plastic behavior. So, in order to estimate ductility, the identification of yield point is necessary and as a yield criterion for timber connections is not well defined, several methods for its determination have been developed [36,37,39,40,41].

In the present paper, Eqs (1) (2) have been used to estimate the level of ductility of the two stop splayed scarf joints samples tested: sample A_D20, unreinforced, and sample B _D20 reinforced with timber pegs. In figure 10, referring to a graph for a specimen of sample B_D20, are identified: $\mathrm{F}_{\mathrm{y}}$ as the force at the yield point, determined by the method based on a 5\% diameter offset, $\mathrm{F}_{\max }$ as the maximum value registered and $\mathrm{F}_{\mathrm{u}}$ as the ultimate force at the failure point.

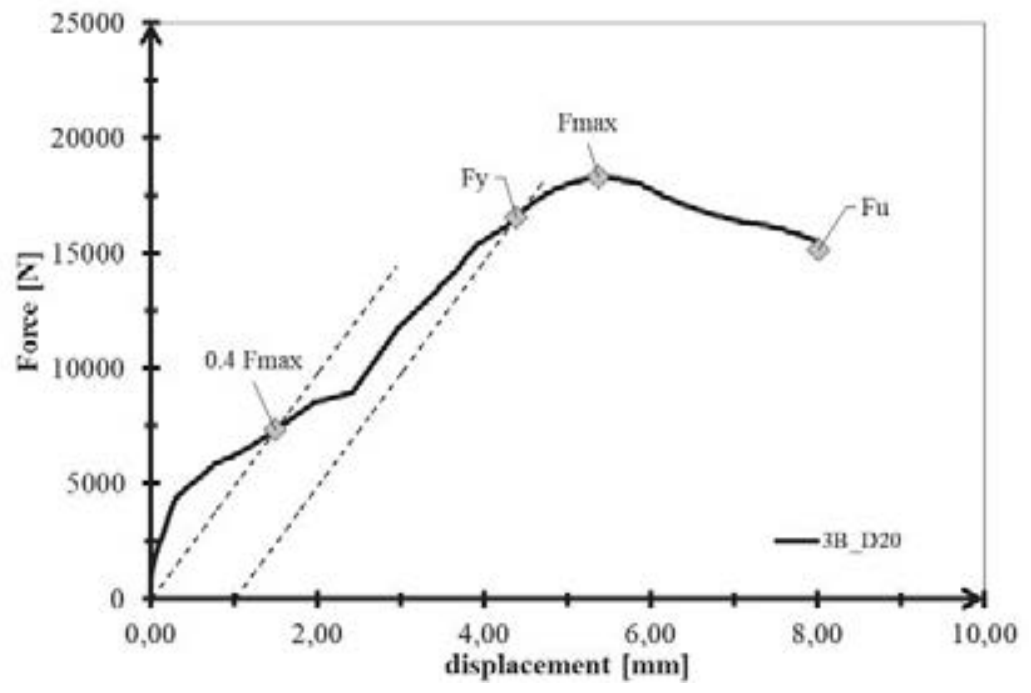

Figure 10: Identification of force values for samples B_D20

A summary of load and displacements at the yield and failure points, for the two samples under consideration is given in Table 3.

\begin{tabular}{|c|c|c|c|c|c|c|c|c|c|}
\hline Specimen & $\begin{array}{c}\mathbf{d} \\
\mathbf{m m}\end{array}$ & $\begin{array}{l}\mathbf{F}_{\mathbf{y}} \\
(\mathbf{N})\end{array}$ & $\begin{array}{c}\mathbf{u}_{\mathbf{y}} \\
\mathbf{m m}\end{array}$ & $\begin{array}{c}\mathbf{F}_{\max } \\
(\mathbf{N})\end{array}$ & $\begin{array}{c}\mathbf{u}_{\mathbf{f}} \\
\mathbf{m m}\end{array}$ & $F_{u}(\mathbf{N})$ & $\begin{array}{c}\mathbf{u}_{\mathbf{u}} \\
\mathbf{m m}\end{array}$ & $\begin{array}{c}\mathbf{D}_{\mathrm{f}} \\
-\end{array}$ & $\begin{array}{c}\mathbf{D}_{\mathrm{u}} \\
-\end{array}$ \\
\hline 1A_D20 & 20 & 11664.1 & 8.1 & 13514 & 8.1 & 3593.8 & 8.21 & 1.00 & 1.01 \\
\hline 2A_D20 & 20 & 10025.0 & 5.6 & 13129 & 5.6 & 5669.5 & 5.74 & 1.00 & 1.02 \\
\hline 1B D20 & 20 & 16507.5 & 8.3 & 21227 & 8.2 & 9807.7 & 8.35 & 0.99 & 1.00 \\
\hline 2B_D20 & 20 & 14701.3 & 3.8 & 15959 & 3.7 & 12944.1 & 4.15 & 0.97 & 1.08 \\
\hline $3 \mathrm{~B}$ D20 & 20 & 16590.3 & 4.4 & 18340 & 5.4 & 15163.5 & 8.01 & 1.23 & 1.83 \\
\hline
\end{tabular}

Table 3: Determination of the displacements at point of yielding $\left(\mathrm{u}_{\mathrm{y}}\right)$ and failure $\left(\mathrm{u}_{\mathrm{f}}\right)$ and ductility ratio based on Eqs (1) and (2).

As can be seen from Table 3 , the ductility values show a uniformity of results in unreinforced and reinforced samples, respectively. Also, the mean value of ductility, at the yield point, in- 
creases by approximately $6 \%$ in the reinforced joint compared to the unreinforced one. Furthermore, the mean ductility value increases if the ultimate displacement is considered. As can be easily seen, in this case the increase in ductility is about $30 \%$. However, evaluating the plastic displacement $\left(u_{f}-u_{y}\right)$ only the reinforced specimen 3B_D20 shows a definite ductile behavior.

\subsection{Role of slenderness}

The present experimental results have also been compared with those obtained in a previous study [12], where an analogous experimental program has been made on smaller scarf joints, unreinforced sample A_D8, and reinforced with two ash pegs of $8 \mathrm{~mm}$ of diameter, sample B_8D (see Figure 11).
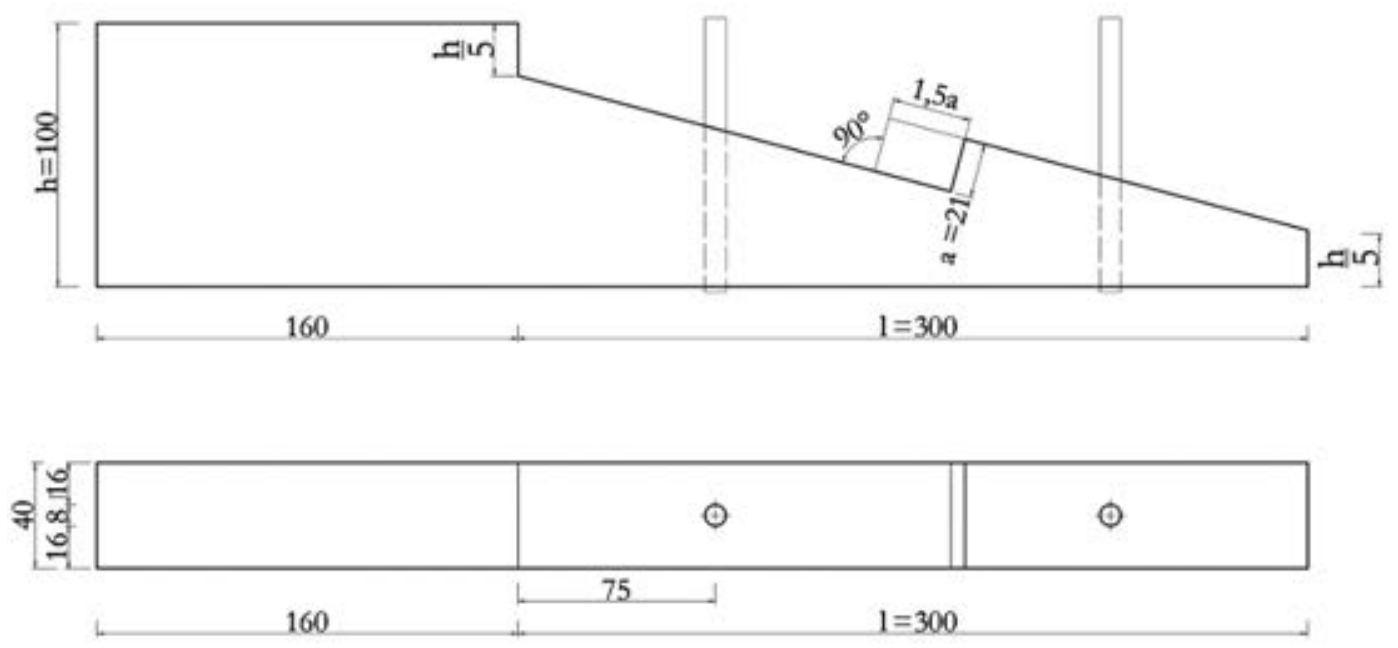

Fig. 11. Specimen geometry of samples A_D8 and B_D8 [12] (dimensions in $\mathrm{mm}$ )

So, the role played by slenderness in reinforcement with timber pegs has been evaluated. In that regard, the slenderness $\lambda$ is defined as follows:

$$
\lambda=\frac{\mathrm{s}}{\mathrm{d}}
$$

where "s" is the smallest thickness of the pegged joint and " $\mathrm{d}$ " is the diameter of peg.

The slenderness values of B_D20D and B_D8 are quoted in Table 4:

\begin{tabular}{c|cccc} 
Specimen & $\begin{array}{c}\mathbf{h} \\
\mathbf{c m}\end{array}$ & $\begin{array}{c}\mathbf{s} \\
\mathbf{c m}\end{array}$ & $\begin{array}{c}\mathbf{d} \\
\mathbf{c m}\end{array}$ & $\boldsymbol{\lambda}$ \\
\hline B_D20 & 140 & 48 & 20 & 2.4 \\
B_D8 & 100 & 44 & 8 & 5.5
\end{tabular}

Table 4: Slenderness values for samples B_20D and B_D8 


\begin{tabular}{c|ccccccc|cc}
$\begin{array}{c}\text { Speci- } \\
\mathbf{m e n}\end{array}$ & $\begin{array}{c}\mathbf{d} \\
\mathbf{m m}\end{array}$ & $\begin{array}{c}\mathbf{F}_{\mathbf{y}} \\
\mathbf{( N )}\end{array}$ & $\begin{array}{c}\mathbf{u}_{\mathbf{y}} \\
\mathbf{m m}\end{array}$ & $\begin{array}{c}\mathbf{F}_{\mathbf{m a x}} \\
\mathbf{( N )}\end{array}$ & $\begin{array}{c}\mathbf{u}_{\mathbf{f}} \\
\mathbf{m m}\end{array}$ & $\mathbf{F}_{\mathbf{u}} \mathbf{( N )}$ & $\begin{array}{c}\mathbf{u}_{\mathbf{u}} \\
\mathbf{m m}\end{array}$ & $\begin{array}{c}\mathbf{D}_{\mathbf{f}} \\
-\end{array}$ & $\begin{array}{c}\mathbf{D}_{\mathbf{u}} \\
-\end{array}$ \\
\hline 1A_D20 & 20 & 11664.1 & 8.1 & 13514 & 8.1 & 3593.8 & 8.21 & 1.00 & 1.01 \\
2A_D20 & 20 & 10025.0 & 5.6 & 13129 & 5.6 & 5669.5 & 5.74 & 1.00 & 1.02 \\
1B_D20 & 20 & 16507.5 & 8.3 & 21227 & 8.2 & 9807.7 & 8.35 & 0.99 & 1.00 \\
2B_D20 & 20 & 14701.3 & 3.8 & 15959 & 3.7 & 12944.1 & 4.15 & 0.97 & 1.08 \\
3B_D20 & 20 & 16590.3 & 4.4 & 18340 & 5.4 & 15163.5 & 8.01 & 1.23 & 1.83 \\
\hline 1A_D8 & 8 & 5849.7 & 5.9 & 6070.5 & 6.7 & 6058.9 & 6.72 & 1.14 & 1.15 \\
2A_D8 & 8 & 6837.6 & 6.4 & 7504.61 & 8.6 & 4772.2 & 15.41 & 1.34 & 2.42 \\
1B_D8 & 8 & 6955.6 & 4.5 & 8678.9 & 12.7 & 6918.3 & 14.10 & 2.83 & 3.13 \\
2B_D8 & 8 & 9264.8 & 6.9 & 9486 & 8.8 & 9327.0 & 9.01 & 1.28 & 1.31 \\
3B_D8 & 8 & 6969.1 & 4.9 & 8770 & 8.5 & 7945.0 & 14.73 & 1.74 & 3.03
\end{tabular}

Table 5: Comparison of samples_D8 and samples_D20

Also, the ductility gain obtained reinforcing the scarf joint with timber pegs is larger for the slenderer samples. In fact, for samples_D8, $D_{\mathrm{f}}$ and $\mathrm{D}_{\mathrm{u}}$ increase of $57 \%$ and $40 \%$ respectively with the reinforcement, while for samples_D20 they increase only of $6 \%$ and $30 \%$, respectively.

\section{CONCLUSION}

The reduced dimensions of the tested samples in this step of the research do not allow definitive conclusions about the influence of reinforcing stop-played scarf joints with timber pegs on ductility. Nonetheless, some interesting remarks have been deduced with can guide modelling the reinforced joint behavior.

First of all, the reinforcement with timber pegs is resulted efficient as it has induced a considerable increase of yielding and maximum forces values with respect to the unreinforced sample and it leads to a ductility increase. A fundamental question is given by the reference point: the European code and Swiss code for timber structures set the reference to the displacement at failure, whereas other methods consider the displacement at ultimate load to evaluate the ductility ratio.

Moreover, the observed rheological behaviors are quite different both in elastic and plastic range. While sample A_D20 shows a liner response in the elastic as well as in the plastic phase, sample B_20, when deformation appears in the simple shear plane joint constituted by the timber peg connection, shows a stiffer behavior in the elastic phase and a more ductile behavior, in the plastic one.

Finally, a more sensitive gain in ductility can be observed when the slenderness is low. In particular, according the Eqs (1-2) for samples_D8, Df and Du increase of 57\% and $40 \%$ respectively with the reinforcement, while for samples_D20 they increase only of $6 \%$ and $30 \%$, respectively. So, in designing reinforcement with timber pegs checking slenderness is necessary, as one of the parameters orienting the choice of peg diameter to be employed.

\section{REFERENCES}

[1] M.A. Parisi, M. Piazza, Mechanics of plain and retrofitted traditional timber connections. Journal of Structures Engineering, 126 (12), 1395-1403, 2000. 
[2] J.M. Branco, M. Piazza, P.J.S. Cruz, Experimental evaluation of different strengthening techniques of traditional timber connections. Engineering Structures, 33, 2259-2270, 2011.

[3] J.M. Branco, T. Descamps, Analysis and strengthening of carpentry joints. Construction and Building Materials, 97, 34-47, 2015.

[4] R. Aman, H. West, D. Cormier, An evaluation of loose tenon joint strength. Forest Products Journal, 58(3), 61-64, 2008.

[5] J. Judd, F. Fonseca, C. Walker, P. Thorley. Tensile strength of varied-angle mortise and tenon connections in timber frames. Journal of Structures Engineering, 137(5), 636-644, 2012 .

[6] E. Likos, E. Haviarova, C. Eckelman, Y. Erdil, A. Ozcifci. Effect of tenon geometry, grain orientation, and shoulder on bending moment capacity and moment rotation characteristics of mortise and tenon joints. Wood Fiber Science, 44(4), 1-8, 2012.

[7] M. Dorn, K. De Borst, J. Eberhardsteiner. Experiments on dowel-type timber connections. Engineering Structures, 47, 67-80, 2013.

[8] B.H. Xu, M. Taazount, A. Bouchaïr, P. Racher. Numerical 3D finite element modelling and experimental tests for dowel-type timber joints. Construction and Building Materials, 23, 3043-3052, 2009.

[9] J. Kunecký, H. Hasníková, M. Kloiber, J. Milch, V. Sebera, J. Tippner. Structural assessment of a lapped scarf joints applied to historical timber constructions in central Europe. International Journal of Architectural Heritage, 12, 666-682, 2018.

[10] A. Arciszewska-Kêdzior, J. Kunecký, H. Hasníková, V. Sebera. Lapped Scarf Joint with Inclined Faces and Wooden Dowels: Experimental and Numerical Analysis. Engineering Structures, 94,1-8, 2016.

[11] R.H. Sangree, B.W. Schafer. Experimental and numerical analysis of a stop-splayed traditional timber scarf joint with key. Construction and Building Materials, 23, 376-385, 2009.

[12] C. Ceraldi, C. D’Ambra, M. Lippiello, A. Sandoli, A. Prota. Structural behaviour of stopsplayed scarf joint reinforced with timber pegs. Construction and Building Materials, 269, 121330-, 2021.

[13] J. R. Aira, F. Arriaga, G. Iniguez-Gonzalez, M. Guaita. Failure modes in halved and tenoned timber scarf joints by tension test. Construction and Building Materials, 96, 360$367,2015$.

[14] E. Perria, M. Paradiso, M. Kessel. Experimental verification of the static model for the characterization of the halved and undersquinted scarf connection. Van Balen \& Verstrynge eds. $10^{\text {th }}$ International Conference on Structural Analysis of Historic Construction, Leuven, Belgium, September 13-15, 2016.

[15] P. Fajman, J. Maca. Stiffness of scarf joints with dowels. Computers and Structures, 207, 194-199, 2018.

[16] P. Fajman. A Scarf Joint for Reconstructions of Historical Structures. Advanced in Materials Research, 969, 9-15, 2014. 
[17] E. Hirst, A. Brett, A. Thomson, P. Walker, R. Harris. The structural performance of traditional oak tension \& scarf joints. $10^{\text {th }}$ World Conference on Timber Engineering (WCTE), Miyazaki, Japan, June 2-5, 2008.

[18] A. Karolak, J. Jasienko, K. Raszczuk. Historical scarf and splice carpentry joints: state of the art. Heritage Science, 8, 105, 2020.

[19] K.W. Johansen. Theory of timber connections. International Association for Bridge and Structural Engineering Publications, 9, 249-262, 1949.

[20] R.J. Schmidt, R.B. MacKey. Timber Frame Tension Joinery. Research. Report, University of Wyoming, Dep. of Civil and Architand Eng, 1997.

[21] C. Ceraldi, V. Mormone, E. Russo Ermolli. Restoring of timber structures: connections with timber pegs. D. D'Ayala and E. Fodde eds. $6^{\text {th }}$ International Conference on Structural Analysis of Historic Construction, Bath, England, July 2-4, 2008.

[22] C. Ceraldi, C. D’Ambra, M. Lippiello, A. Prota. The Influence of Dowel-Bearing Strength in Designing Timber Pegged Timber Joints. International Journal of Architectural Heritage, 12, 3362-375, 2018.

[23] I. Teodorescu, B. Pereira, C.D. Aquino, J.M. Branco. Experimental evaluation of doweltype timber joints with wooden dowels. Proceedings of the Institution of Civil Engineers - Structures and Buildings, https://doi.org/10.1680/jstbu.20.00021.

[24] R.J. Schmidt. Timber Pegs - Considerations for Mortise and Tenon Joint Design. Structural Magazine, 3, 44-47, 2006.

[25] J.F. Miller, R.J. Schmidt, W.M. Bulleit. New Yield Model for Wood Dowel Connections. Journal of Structural Engineering, 10, 1255-126, 2010.

[26] R.J. Schmidt, G.F. Scholl. Load Duration and Seasoning Effects on Mortise and Tenon Joints. Research Report, University of Wyoming, Dep. of Civil and Archit and Eng, 2000.

[27] C. Ceraldi, M. Lippiello, E. Russo Ermolli. Connections with timber pins: the influence of dowel-bearing strength. Proceedings of International Conference on Structural Health Assessment of Timber Structures, Lisbon, June 16-17, 2011.

[28] C. Ceraldi, C. D’Ambra, M. Lippiello, A. Prota. The Influence of Dowel-Bearing Strength in Designing Timber Pegged Timber Joints. K.Van Balen and E. Verstrynge eds. $10^{\text {th }}$ International Conference on Structural Analysis of Historic Construction, Leuven, Belgium, September 13-15, 2016.

[29] R.J. Schmidt, J.F. Miller. Capacity of Pegged Mortise and Tenon Joinery. Research Report, University of Wyoming, Dep. of Civil and Archit and Eng, 2004.

[30] C. Ceraldi, M. Lippiello, E. Russo Ermolli. Timber pins connections: reliability of bolted joints design rules. J. Jasieńko ed. $8^{\text {th }}$ International Conference on Structural Analysis of Historic Construction, Wroclaw, Poland, October 15-17, 2012.

[31] C. Ceraldi, C. D’Ambra, M. Lippiello, A. Prota. Restoring of timber structures: connections with timber pegs. European Journal of Wood and Wood Products, 75(6), 957-971, 2017.

[32] J. Milch, J. Tippner, M. Brabec, V. Sebera. Experimental Verification of Numerical Model of Single and Double-Shear Dowel-Type Joints in Wood. H. M. Barnes and V. L. 
Herian eds. $57^{\text {th }}$ International Convention of Society of Wood Science and Technology. Zvolen Slovakia Technical University, 2014.

[33] A. Jorissen, M. Fragiacomo. General notes on ductility in timber structures. Engineering Structures, 33, 2987-2997, 2011.

[34] K. A. Malo, J. Siem, P. Ellingsbø. Quantifying ductility in timber structures. Engineering Structures, 33, 2998-3006, 2011.

[35] H. J. Blaß, P. Schädle. Ductility aspects of reinforced and non-reinforced timber joints. Engineering Structures, 33, 3018-3026, 2011.

[36] EN 12512-2001: Timber structures - test methods-cyclic testing of joints made with mechanical fasteners.

[37] SIA 265:2012 Holzbau. Schweizerischer Ingenieur-und Architektenverein, 2012.

[38] ASTM D 5764 - 97a: Standard Test Method for Evaluating Dowel-Bearing Strength of Wood and Wood-Based Products. ASTM International.

[39] E. Karacabeyli, A. Ceccotti. Nailed Wood-Frame Shear Walls for Seismic Loads: Test Results and Design Considerations. Proceedings, Structural Engineering World Wide, Paper Reference T207-6, 1-9, 1999.

[40] M. Yasumura, N. Kawai N. Estimating seismic performance of Wood-framed structures. Proceedings of $5^{\text {th }}$ World Conference on Timber Engineering, 2, 564-571, 1998.

[41] C. G. Foliente. Issues in seismic performance testing and evaluation of timber structural systems. International Wood Engineering Conference, October 28-31, New Orleans, USA, 1996. 